CASE VIII.

Medical man, aged 35. Occasional attacks of migraine for some years with marked visual phenomena and headache but no vomit ing. In 1922 there were five attacks within a short period and in four of these sbsolute and immediate relief was obtained after taking taking calcium lactate. In the fith attack no supply of the drug could be obtained and the consequent headache lasted for more than twenty-four hours. After

Case ra.

Medical man, aged 26. Typical migraine attacks unaccompanied by vomiting since February, 1923 . I ordered calcium lactate in the usual dose. He reports (October, 1923) that he has experienced eighteen attacks, of which fifteen were aborted by the treatment and no headache resulted. In two of the remaining three attacks no calcium lactate was taken and in the third the dose was taken too late, with the result that headache followed in each instance.

Case $x$.

For notes of this case I am indebted to Dr. E. I. Claxton of Bootle. Woman, aged 47. This patient had had recurrent headaches, showing all the typical events of the migraine syndrome, since she was 7 years of age. At first the attacks were at monthly intervals, but since reaching the age of 30 they have become more frequent. In November, 1922, luminal was exhibited, but this drug, even in small and widely separated doses, made the patient so drowsy that its use had to be discontinued. Speaking of this patient the doctor wrote in a letter received in September of this year: "After hearing your note read at the Liverpool Medical Institution on January 4th, 1923, I put he on a 30-grain dose of calcium lactate, which must be taken within half an hour of the appearance of the visual symptoms. This aborts the attack; the only time it failed was when she neglected taking the dose within the prescribed half-hour." $\mathrm{He}$ adds : " feel convinced that this drug is the only one that has given relief to a patient who has been a life-long sufferer from migraine." It is only fair to add that in a verbal communication Dr. Claxton has since informed me that quite recently the patient has vomited on one or two occasions.

Dr. J. Flanagan of Bootle reports that he has tried my method of treatment in three typical migraine cases occurring in women during the last nine months. The attacks were aborted in all.

No object is to be gained by multiplying such examples; suffice it to say that, in my series of 20,16 patients stated that their attacks have been aborted by the calcium lactate treatment. Of the remaining 4,2 were apparently cured by general remedies and consequently had no need to try calcium, and 2 experienced no relief. Of these two apparent failures one is a medical man whose case is complicated by a gunshot wound of the skull, and in his attacks he experiences great pain in the region of the scar; the other is the wife of a friend whom I have only treated by proxy, and possibly she may not be suffering from true migraine at all.

It is not right that definite conclusions should be drawn from such a small series of cases. Nevertheless, I have taken the opportunity of publishing my results in order that this treatment may be tried on a wider scale and its efficiency proved.

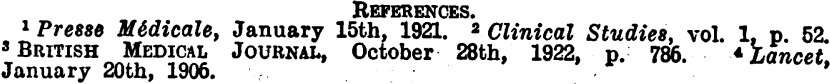

\section{THE NATURE AND TREATMENT OF SPRUE.*} BY

H. H. SCOTT, M.D., M.R.C.P.LoND., D.P.H., D.T.M. AND H.CAMB., F.R.S.EDIN.,

ASSISTANT IN HFLMINTHOLOGY, LONDON SCHOOL OF TROPICAL MEDICINE.

VARIoUs theories of the causation and modes of treatment of sprue have been advanced, but hitherto treatment has been almost entirely empirical. The method I wish to bring forward has at least the merit of a rational basis. The best way in which I can briefly place before you the line of reasoning on which the theory first originated is to relate the history of a patient a consideration of whose symptoms and progress formed the basis of the theory.

The patient in question contracted the disease in China in 1920. The usual symptoms were present: the loss of weight was rapid, sometimes $3 \mathrm{lb}$. in a week, and the mouth symptoms were very severe. On more than one occasion there were over thirty aphthae in the mouth, so that the taking even of milk was painful. These spots are spoken of as aphthae, but they differ from what we usually recognize under this term. After a bout of "acidity "-burning pain

* Read at a meeting of the Section of Tropical Medicine and Parasitology in the stomach with acid rising into the oesophagus-there would ensue in twenty-four hours or so a crop of four or five very tender spots on tho tongue, the fraenum, or the level of the second molar, or on the gums and cheek. There was nothing visible at this early stage, but in a few hours small red patches would develop which in another twentyfour to thirty-six hours would break through or become abraded and intensely painful little ulcers would appear.

Another symptom not mentioned in the books, but very marked in this case, and in many others whom I have questioned, was cramps, or rather carpo-pedal spasms. Tetany is spoken of, but the former is, in my opinion, much more common. During the night the patient frequently had to spring out of bed and pace the floor to relieve these cramps of the legs and feet; when writing, cramps of the hands would come on, so that the penning of more than a brief letter became impossible.

He suffered many things of many physicians. He took nearly all the rellow santonin there was in the colony; he was given autogenous vaccines (Streptococcus salivarius and others), emetine injections, was dieted with milk at one time, with the Salisbury method at another, with a diabolical preparation to which sprue itself is, in my opinion, preferable-namely, liver soup-at a third. Finally, he was sent on a voyage to Canada with the idea that a "spell of cold weather would drive out the sprue."

After some months, during which he became progressively worse, he managed to crawl with aid on to a vessel for England, and arrived in March, 1922. He was taken into hospital the following day, fortunately under the care of one who had for years been studying the disease both at home and in its endemic centres abroad. Confinement to bed and a milk diet for some weeks led to considerable improvement, and the patient went to the country to convalesce. Any attempt, however, at passing on to even decent invalid food led to more sore mouth, more flatulence, acidity, large stools, loss of weight-in fact, to a return of the typical symptoms. Two relapses occurred during the ensuing nine months, and the patient was invalided from the service in consequence. At each of the relapses the cramps returned as badly as ever.

I now began to ponder whether it was not possible to trace to some common origin these various symptoms. Dyspepsia and large pale, pasty motions are amongst the earliest manifestations. The stools show a relative excess of fatty acids and a relatively large excretion of calcium. The urine also in some cases contains more calcium than normal. The flatulence, acidity and diarrhoea, the aphthae, languor, and loss of weight, might all arise from states of intestinal intoxication. Next came to mind the peculiar association of carpo-pedal spasms with calcium deficiency, the correlation possibly of these with the diarrhoea and intestinal toxins, referring them to the group of organs which have been credited with the control of both these conditions-the parathyroids. These are believed to have a twofold function-namely, the regulation of calcium metabolism and of detoxication, in particular of the poisons of intestinal origin. In addition to this, but as subsidiary and not acting in all cases, is the condition of hyperchlorhydria. If this is present we may have as a result an excessive production of secretin by the action of the acid of the gastric juice upon the prosecretin of the mucous membrane of the duodenum. Excess of secretin leads to stimulation of the pancreas with an increased splitting up of fats, so that the normal ratio of neutral fats to fatty acids is diminished, as I have detailed in a former paper. This, however, is but a side issue, and does not come into play in all cases, for in sprue the gastric contents may show hyperchlorhydria, normal acidity, or hypochlorhydria.

Here was enough to start on. Examination of the blood revealed the fact that the total calcium was little, if at all, diminished, except in later stages or in very severe cases, nor was the coagulation time prolonged. The inference, therefore, was that in spite of the loss of calcium in the excreta sufficient was being absorbed to maintain the normal total calcium in the blood.

Calcium, according to the researches of Vines and Grove; is present in the blood in two forms-the ionic or free, and the combined or coagulative. Seeing that the latter was 
not deficient, although the symptoms pointed to calcium deficiency, it was inferred that the ratio between the two might possibly be upset. In the blood plasma there is normally between 10 and $11 \mathrm{mg}$. of calcium per 100 c.cm., of which $6.5 \mathrm{mg}$. or thereabouts is in the ionic state and the jemainder combined. This latter fraction is concerned with the process of coagulation, and during the clotting this $4 \mathrm{mg}$. of " combined" calcium becomes changed to free calcium, due to the breaking down of a calcium-lipoid complex. In normal persons the whole of the $10 \mathrm{mg}$. should, after the blood has clotted, be in the free state in the serum - that is, there should be no residual combined calcium. In conditions of so-called "calcium deficiency" the blood after clotting is found still to contain some calcium in the combined form, and there is thus a relative deficiency of ionized calcium.

Calcium in the form of the lactate was then prescribed for the patient and the symptoms improved, but though the drug was continued relapse took place. Further increase of the calcium led again to improvement, followed again by relapse. Perhaps the augmented intake brought the ionic calcium temporarily to the normal, and the relapse would then be explainable by the ratio again becoming, or still remaining, disarranged. The amount of the calcium was then reduced and parathyroid extract was given. I am not sure now whether the former drug need be given at all, since the food as a rule contains sufficient calcium for the needs of the body. A wonderful change took place. Developed aphthas rapidly healed, commencing ones, as sore papillae and tender spots, receded without becoming aphthae, the flatulence was diminished, the stools became fewer and smaller, the colour began to return, and the general sense of well-being was regained. Within so short a time as a fortnight all the more acute symptoms had disappeared; food was increased, calcium was stopped, and in five weeks the patient was on ordinary diet. The parathyroid was gradually left off, and in six weeks from its first employment was stopped altogether. Nearly eleven months have gone by and he has lived a normal life, working hard Sundays and weekdays, paying no regard to diet, taking alcohol on occasion, and has not had a day's illness since.

This is not altogether an exceptional case. I have records of other patients who have done nearly, some quite, as well; one even better.

Let me now briefly review the symptoms associated with calcium deficiency, or, as it is preferable to call it, irregularity of calcium metabolism, and see how they apply to the disease we are discussing.

When the European goes to the East-for instance, to India-he continues to indulge his preference for a meat liet and partakes also of some of the native dishes, such as curries and highly seasoned rice. His thirst is slaked by iced drinks, often sweetened, and sometimes containing a considerable quantity of alcohol. His diet there is thus in several ways unnatural, and hyperchlorhydria is common. The effect of this I have already mentioned elsewhere. Gastric and intestinal disturbances are commonly associated with stomatitis and aphthae. The excess of acids in the food also plays a notable part in sprue; the saliva itself is, in many cases, acid.

In other countries where sprue is endemic-China and Porto Rico for example, to instance places in the Far East and in the West-the food and the methods of cooking lead to an increased ingestion of fats. Kochmann and Petzsch by adding fats to the diet of healthy dogs showed that a considerable loss of calcium occurred, while Rothberg and others noticed that in children to whom an excess of fats was given the retention of calcium was reduced. This they explained by the increased formation of calcium soaps in the intestine, unabsorbed fatty acids being eliminated in the stools as soaps of potassium, sodium, and calcium, leading thereby to the impoverishment of the body in respect of bases. Again, Korenchevsky found that in animals on a diet deficient in calcium. diarrhoea was noticed, together with such symptoms as loss of weight and increased nervous excitability.

How far vitamin action comes into play $I$ do not venture to say, though, according to Aulde, a lack of calcium when vitamins are supplied induces the same changes in the endocrine glands as are seen in conditions where calcium in the diet is abundant but the vitamins are deficient. In other words, vitamins are unable to fulfil their function in the absence of inorganic salts.

In calcium starvation (accompanied by deficiency of fatsoluble factors in the diet) there is a considerable loss of calcium and phosphorus from the organism. Korenchevsky found in his experiments that administration of calcium salts under these conditions led to a temporary improvement in the balance of calcium, but as soon as the extra intake ceased the retained calcium was soon excreted. Before I came across the account of Korenchersky's work $I$ had stated that this was what probably occurred in sprue. The taking of calcium led to improvement of symptoms, but the dose had to be increased because, so I inferred, it was being improperly regulated. If we think for a moment of the nutrients recommended for spruecertain fruits, milk, carrots, young spinach, potatoes-we see that all are characterized by an excess of bases and a richness in calcium.

The amount of calcium in the blood does not depend solely, or even in the main, upon the amount of calcium salts taken in the food or as medicine, but on the efficiency of the calcium-regulating mechanism-the parathyroids with their twofold function of detoxication and regulation of calcium metabolism. The mechanism of this regulation would naturally be upset if the toxins were more than could be dealt with, and the absorption of certain toxins appears to lead to such disturbance; the ionic calcium suffers diminution and becomes relatively deficient first, while in the later stages there is an absolute deficiency. Calcium deficiency is therefore regarded as an indication of toxin absorption.

In cases of sprue, then, we have one of two conditions. In the one where fats are in excess we have an excessive excretion of calcium in addition to intoxication of intestinal origin; in the other protein excess with intestinal toxin formation. In both, the parathyroid detoxicating function is overburdened, with a resultant disorganization of its calcium-regulating function, while there may be in addition diminished calcium absorption. Both functions, therefore, of these glands are interfered with.

A few figures of the calcium content of the blood of a normal person and of patients suffering from sprue are given in the table. The specimens were sent to Dr. H. W. C. Vines, of the Cambridge Medical Schools, Fellow of Christ's College, who very kindly undertook to examine with regard to their calcium content specimens of blood sent up. He was not told the histories of the cases when the specimens were sent, and I think it will be agreed that the results obtained afford remarkable corroboration of the theory I have brought forward.

Table of Calcium Contents of Blood Normal and in Cases of Sprue.

\begin{tabular}{|c|c|c|c|}
\hline & Free Ca. & $\underset{\text { Ca. }}{\text { Combined }}$ & $\begin{array}{l}\text { Total in } \\
\text { mg. per } \\
\text { 1C0 c. cm. } \\
\text { serum. }\end{array}$ \\
\hline Normal (after clotting) $\quad \ldots \quad \ldots \quad \ldots$ & 10.7 & 0.0 & 10.7 \\
\hline $\begin{array}{l}\text { McG. Fairly severe case. } \\
\text { Before starting treatment } \quad \ldots \\
\begin{array}{l}\text { After one week } \\
\text { After two weeks (good progress) }\end{array}\end{array}$ & $\begin{array}{r}6.1 \\
8.1 \\
10.1\end{array}$ & $\begin{array}{l}3.8 \\
1.8 \\
0.0\end{array}$ & $\begin{array}{r}9.9 \\
9.9 \\
10.1\end{array}$ \\
\hline 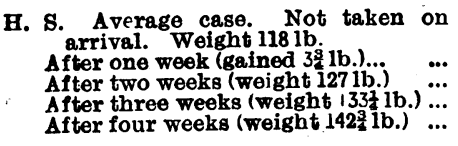 & $\begin{array}{r}7.0 \\
7.4 \\
10.8 \\
10.8\end{array}$ & $\begin{array}{l}2.9 \\
2.7 \\
0.0 \\
0.0\end{array}$ & $\begin{array}{r}9.9 \\
10.1 \\
10.8 \\
10.8\end{array}$ \\
\hline $\begin{array}{l}\text { C. W. Mild case : nine months ill. } \\
\text { (Bombay.) } \\
\text { Before starting treatment .. } \\
\text { After two weeks (to have fish, } \\
\text { chicken, potatoes, milk, biscuits, } \\
\text { carrots, eggs } \\
\text { After three weeks (to have meat, } \\
\text { beef, mutton, ordinary food } \\
\text { After four weeks, reported him- } \\
\text { self quite well, } 21 \text { b. above normal } \\
\text { weight. }\end{array}$ & $\begin{array}{r}8.0 \\
8.9 \\
10.4\end{array}$ & $\begin{array}{l}1.9 \\
1.2 \\
0.0\end{array}$ & $\begin{array}{r}9.9 \\
10.1 \\
10.4\end{array}$ \\
\hline
\end{tabular}

It will be seen that in a case of somewhat severe sprue before commencing treatment there was a reduction of 
more than one-third in the ionic calcium, though the total was very little reduced. In all, as they progressed, this figure went up, almost pari passu, and when the free calcium reached normal and there was no residual combined calcium the patients expressed themselves as feeling well and very hungry, and there were no untoward symptoms.

In my previous paper records were given of individual cases and also an explanation, or possible explanation, of the rationale of the modes of treatment in vogue. There is no need to repeat these, but as Sir Leonard Rogers believes so strongly in the efficacy of vaccines in this disease and has reported many good results, I may perhaps be allowed to say a word or two on that head, as it bears on my own theory. According to what I have advanced the detoxicating function of the parathyroids becomes overtaxed; it has been working overtime, as it were, for probably a considerable period, and has finally had to succumb or at least take a temporary rest. The organism cultured from the mouth or stool is only one of several which may have had a hand in the toxin production, and the effect of the vaccine would be to render one of the foes hors de combat and reduce the inimical influences to such an extent that the parathyroids can now cope with them, especially when the treatment is combined with mental and bodily rest in bed and an addition of calcium by a diet consisting largely of milk. This explains, I think, the good results obtained from so many different vaccines, provided they are autogenous.

\section{"There are twenty different ways} of writing tribal lays,

And every single one of them is right,"

says Rudyard Kipling. It may be the same in sprue. Twenty different men might find twenty different organisms, make vaccines from them, and report good results in each case, for they might each have hit off an organism responsible, in part at least, for the toxin produced in each individual patient, and by combating it relieve the overworked parathyroid and enable this gland to take up its duties again. But no single vaccine would prove effectual in all cases, and we may thus explain the individual good results of streptococci in some of Sir Leonard Rogers's patients, of monilia in Ashford's, of coliform bacilli in various others.

Auother form of treatment, highly commended by some in the Far East, is powdered crabs' eyes and cuttle-fish shell. I do not know the chemical composition of the former, but the latter contains much calcium. Another favourite medicine is pulvis Bataviae co. What is this but concentrated calcium?

It has already been stated that the foods found best for sprue patients contain quantities of this base. In a word, the best diet and the most successful drugs hitherto used have supplied abundant calcium, a base which serum analyses have shown to be deficient-sometimes absolutely, more often relatively-without exception in those tested so far. The constituent parts are ill balanced, and the disease, therefore, calls imperatively, not so much for a more abundant supply of calcium as for support in regulating its disposal - that is, for parathyroid. The rest in bed, which is important in the early stage of treatment, puts the whole system under the best conditions for recovery of function.

When I wrote the last communication on this subject $\mathbf{I}$ could only speak of patients treated in Fingland, but $I$ stated that it would be of interest to know whether such felicitous results could be obtained abroad as I had had here with cases which, by the great kindness of the physicians to the Hospital for Tropical Diseases, I had been permitted to see in addition to those whom I myself had treated outside. $I$ have since had reported to me the cases of eight patients in the Far East all of whom had been under the usual methods of treatment for one and a half years or more. One had come to this country for treatment, and, having been kept for a long time in hospital, had been obliged to return. He was assured that he would not live through the voyage, and, in fact, was carried ashore on a stretcher. He started the calcium and parathyroid treatment; in three weeks was up and about, and in five was carrying on his business.

If such fortunate results can be obtained in countries where the disease is endemic (and in most of these its prevalence appears to be increasing), much sickness and invaliding will be avoided and not a few deaths prevented, a marked contrast to what obtains at present-a miserable voyage home on ship's food, a stay of several months in hospital on the diet of a toothless infant, followed by months of food restriction, an ever-present haunting dread of a recurrence of symptoms, and a veto on any idea of a return to a tropical climate; in other words, the ruin of many a young man's career.

\section{(2)ritish Attediral Assariation.}

\section{PROCEEDINGS OF SECTIONS AT THE ANNUAL MEETING, 1923.}

\section{SECTION OF MEDICINE.}

Sir Thomas J. Horder, Bt., M.D., F.R.C.P., President.

\section{DISCUSSION ON CHRONIC BRONCHITIS.}

\section{I.-JOSEPH JOHN PERKINS, M.A., M.B.CAMB., F.R.C.P.LoND.}

Consulting Physician, St. Thomas's Hospital.

Tirs subject before us this morning, which may secm a very sinple one, was chosen in deference to the fuelings expressed by Branches that hronchitis was well worth discussion, on account of the frequency of theic ciists in practice and the high death roll that follows-the Registrar-General's figures for 1920 were 1,010 deatl.s per million living.

I'he Branches felt that little advance had becin made in treatment, except perhaps that with come men it routime use of vaccines has talien the place of a routine grivine of expectorants, and they hoped that a comparison of comusels which Sophocles has said is characteristic of the Wis., might lead to improvement in treatment and cren night help towards prevention also.

The Committee agreed and accepted the suggestion, lint decided that the time at our disposal would not admit of a discussion of the whole subject, including acute bronclitis and pulmonary lesions consequent on bronchitis. They therefore limited the subject to recurrent and chronic catarrh of the trachea and bronchi.

I shall be brief in my opening remarks, and will first outline the ground which will be covered this morning.

Catarrh, one may say, is immediately due to invasion by infecting organisms. Dr. Inman and others will deal with the bacteriological aspect of the subject and the vinie to be placed on vaccines. But we may go deeper than the question of immediate trentment, and consider the possibility of prevention. Preventive anticatarrhal inoculation is a method largely used, of the value of which many members hold a high opinion. This, we hope, will conio into the discussion this morning, and we expect to get some solid information from their experience.

Further, are there not conditions which predispose in individual cases to recurrent bronchitis and invasion by inicro-organisms? If such can be found and dealt with treatment and prevention will be placed on $\Omega$ sounder footing. In other words, to use the well lnown similn, the soil should be borne in mind as well as the seed.

Predisposing conditions would seem to fall under itie following heads: (1) The part played by occupations and trades; on this Professor Collis has sent in a slort statement in which he emphasizes the importance of " atuicospheric pollution" in the causation of bronchitis. His paper, with full statistics, will appear is print shortly. (2) The part played by clinate in causation and treatruen: (3) How far are pre-existing local pathological conditions present, especially in the upper respiratory tract, in these patients, with the result that they carry in themselres a 